\title{
CONSIDERATIONS For DEVELOPMENT OF CRITICAL REFLECTION SKILLS IN FIRST-YEAR ENGINEERING InFORMED Through STUdent PERSPECTIVES
}

\author{
Elizabeth DaMaren ${ }^{l}$, Danielle Pearlston ${ }^{l}$, Stephen Mattucci ${ }^{1,2}$ \\ ${ }^{1}$ McMaster University, ${ }^{2}$ Canadian Engineering Education Challenge \\ mattucs@mcmaster.ca
}

\begin{abstract}
Reimagined curriculum models offer new possibilities for embedding durable competencies into the curriculum, including critical reflection, which promotes the development of self-directed learning skills. However, students often perceive these skills as unimportant with pre-existing biases focusing on technical content as the core of engineering. The primary goal of this work was to identify key considerations when integrating critical reflection into engineering curricula, specifically in the context of first-year engineering, to promote the development of student self-directed learning skills.

This work was framed within the Students-as-Partners (SaP) approach, where two undergraduate students worked in collaboration with the instructor. To gather information regarding student perceptions of critical reflection, focus groups were conducted for first-year engineering students and students familiar with reflection.

Qualitative thematic analysis was performed on the focus group data and key insights were identified and categorized into five themes: approaches, supporting students, evaluation and framing, development pathway and value, and reflection for engineers. Suggested learning outcomes, student activities, and evaluation methods are proposed. These findings are applicable to implementing reflection across a variety of academic settings, as they highlight main considerations and challenges faced with reflection from the perspective of students in multiple programs.
\end{abstract}

Keywords: critical reflection, self-directed learning, student perspectives, first-year engineering, curriculum considerations

\section{MOTIVATION}

In recent years, several Canadian engineering institutions have begun developing integrated pedagogical approaches that use experiential and project-based learning strategies in first-year curricula. At the University of British Columbia, two new first-year engineering courses focus on hands-on learning through projects to gain an understanding of fundamental engineering concepts [1]. The University of Saskatchewan has been undergoing an overhaul of their first-year engineering program which looks to restructure the year in favour of a more engaging and modular curriculum which better prepares students for learning in upper years and beyond [2]. McMaster University's Faculty of Engineering is transitioning to a curriculum that highlights the values of experiential learning through the PIVOT transformation [3]. The aim is to equip students with complex problem-solving skills, critical thinking skills, and creativity to prepare them to meet the challenges of a rapidly changing world. This transformation will introduce project-based learning into first-year engineering to begin student development of these skills at the onset of their university careers.

When durable (i.e. professional-, non-technical-, etc.) skills are not embedded in curriculum, students often enter the workforce underprepared. Issues reported in the Canadian employment landscape show that young professionals are graduating with highly specific training, but without necessary foundational skills transferable between jobs [4-5]. A 2018 research study reported that, in the coming decade, half of all jobs will go through a significant overhaul of skills required. Additionally, employers state that these foundational skills are more important than a student's choice of undergraduate major [5] and will play a crucial role in the employability of graduating students. Incorporating skills such as critical thinking, social perceptiveness, and lifelong learning in undergraduate education can help students become more flexible and prepared for a wide variety of jobs.

The use of critical reflection to promote self-directed learning competencies is particularly valuable in early years of university as students are solidifying their learning skills. In an engineering context, reflection has helped students connect what they have learned in the classroom to job knowledge and skills, allowing them to better apply their knowledge to real scenarios [6]. Reflective practice has also shown to be an important skill for practitioners, such as engineers, in recognizing and understanding learnings that come out of experiences [7]. 
Self-directed learning through reflection has many benefits, including improved student performance, critical thinking, and oral communication skills [8-9]. The importance of self-directed learning can also be seen in the Canadian Engineering Accreditation Board's Lifelong Learning Graduate Attribute [10]. In an ever-changing world, it is crucial to empower students to take charge of their learning, using skills like critical reflection, so they can continue to develop skills throughout their careers.

Integrating reflection in coursework is ongoing at McMaster University in faculties outside of engineering. A Reflective Learning Framework (RLF) has been developed which outlines how reflection can be used to solidify learning from experiential education activities [11]. This framework has a comprehensive evaluation structure and can be utilized in a variety of course settings; however, it was designed for senior-level courses and may not be suitable in first-year contexts.

Despite the clear need of self-directed learning and critical reflection in engineering, there are few examples in the literature of implementing critical reflection into engineering curricula. Those that do often report challenges, such as uncertainty in what format of selfreflection tools are best [12], logistical challenges of providing feedback, and difficulties with eliciting genuine responses [8]. Further, anecdotal discussions within the engineering education community point to the tendency of student reflections to remain superficial (i.e. simply describing experiences), and the challenge of convincing students of the value of this approach with competing priorities in heavily-loaded, technically-focused curricula.

The primary goal of this work was to identify key considerations when integrating critical reflection into engineering, specifically in first-year curricula, to promote the development of self-directed learning skills.

\section{FRAMING AND PROCESS}

\subsection{Conceptual Framework}

This work was conducted with the Students-asPartners ( $\mathrm{SaP}$ ) model where students are collaboratively involved in pedagogical pursuits [13]. SaP allows for insight from the student perspective and can lead to more inclusive teaching practices and increased self-awareness and motivation for teaching staff [14]. When integrating reflection into curriculum, the $\mathrm{SaP}$ approach brings significant benefit as durable skills, such as reflection, are often not perceived as valuable to the student population. Therefore, the student's perspective on the value of reflection and realistic approaches to engage students are critical to a successful implementation.

The instructor (Mattucci, postdoctoral fellow) values student ownership of learning as a core tenet of his teaching philosophy and has had past success involving students in the development process. Mattucci has previously integrated reflection into a senior-level experiential learning course where students earn credit for extracurricular roles, and reflection serves as the primary assessment mechanism [15].

The reflector student partner (Pearlston, third-year Health Sciences) has extensive experience with reflection as it is highly integrated into her undergraduate program. Pearlston has been privy to the educational benefits of inquiry-based learning, where she feels critical reflection plays a significant role. As a partner in curriculum development, Pearlston brings a passion for educational innovation and a student perspective on the successful integration of reflective practice into curriculum.

The engineering student partner (DaMaren, fifth-year Mechatronics Engineering \& Society student) was previously involved in early consultation for the technical content of the first-year engineering curriculum overhaul. As a current engineering undergraduate student, she could offer firsthand insights into the experience of an engineering student. Having recently been exposed to reflection in-depth in several courses in her senior years, DaMaren saw opportunities for and the value in developing these skills earlier in university.

\subsection{Team-Generated Approach}

A critical component of the SaP model is to involve students as partners on all aspects of a project, including planning phases. An initial meeting involved identifying constraints and key information required to inform the curriculum development process, as well as the respective strengths and expectations of all team members. The intricacies of the student-faculty dynamic on this project, in specific, are analyzed from a reflective lens in a separate study [16].

After consultations with engineering faculty members, the voice from the most important stakeholder group was needed: students. The team brainstormed key questions concerning the project and subsequently used these to form focus group questions.

\subsection{Focus Groups / Data Collection}

Student perspectives on important aspects of reflection were obtained through focus groups for two student populations: first-year engineers, and 'experienced reflectors.' The first-year students were the target population for the curriculum overhaul, and the 'experienced reflectors' were students from any program who were familiar with reflection practice, either through previous coursework or external contexts. The information obtained was intended to be as general as possible to be relevant to other contexts, not just first-year engineering. The team obtained ethics permission from the McMaster Research Ethics Board for this study (MREB \#2550).

Eight focus groups were held over four sessions, with a total of 38 students participating across all sessions. Each session contained two focus groups, one with the first- 
year engineering students, and another with the experienced reflectors. One student partner ran each focus group to encourage candid responses from peer-to-peer interactions, with the instructor providing assistance if needed. Notes were taken by the student partners, omitting identifiable information to ensure anonymity in any ensuing analysis. Prompts were used to gather information according to question categories (Table 1).

Table 1: Focus group example prompts.

\begin{tabular}{|l|l|}
\hline \multicolumn{1}{|c|}{$\begin{array}{c}\text { Question } \\
\text { Categories }\end{array}$} & \multicolumn{1}{c|}{ Example Prompts } \\
\hline $\begin{array}{l}\text { Establishing } \\
\text { Context }\end{array}$ & $\begin{array}{l}\text { In what context(s) have you engaged in } \\
\text { reflection to date? }\end{array}$ \\
\hline $\begin{array}{l}\text { Motivation and } \\
\text { Value }\end{array}$ & $\begin{array}{l}\text { Do you think reflection is or could be } \\
\text { valuable to you? Why or why not? }\end{array}$ \\
\hline Implementation & $\begin{array}{l}\text { Do you think you would find reflecting on } \\
\text { personal values or the course content more } \\
\text { valuable? }\end{array}$ \\
\hline Evaluation & $\begin{array}{l}\text { How would you feel about reflections being } \\
\text { graded by peers? TAs? Would that } \\
\text { influence what you write? }\end{array}$ \\
\hline Lasting Impact & $\begin{array}{l}\text { How might you approach reflection if you } \\
\text { knew you would encounter it again? (i.e. in } \\
\text { future courses, career) }\end{array}$ \\
\hline
\end{tabular}

\subsection{Data Analysis}

The focus group data was qualitatively analyzed for thematic similarities. Together, the team coded the information from one session for preliminary themes. Using these themes as a guideline, each member went through all notes individually to code the data. When all documents had been coded, the categories that had been identified through the first round of analysis were used to generate a final set of codes, which DaMaren used for a final coding of the notes. This final coding was used in synthesizing final themes and key outcomes of the focus groups.

\section{FOCUS GROUP OUTCOMES}

Seventeen codes were created through the data analysis process (Table 2), which were then synthesized into a final set of themes related to integrating critical reflection into first-year engineering curriculum: approaches, evaluation \& framing, supporting students, development pathway \& value, and engineering toolkit (Fig. 1).

\subsection{Approaches}

Approaches refers to both the methods of introducing the concept of critical reflection and considerations for how to implement reflection in academic settings. Reflection will not be a novel concept for students - most people have some experience with reflection, even if they do not realize it. Common forms of reflection include journaling and discussing group projects and how things could have been done better, which students may not realize can be reflection. Students in focus groups highlighted that presenting these familiar contexts can help frame reflection in students' minds as less of an assignment and more of a tool they recognize and have used previously.

Table 2: Focus group code descriptions.

\begin{tabular}{|c|c|}
\hline Code & Description \\
\hline $\begin{array}{l}\text { Flexibility } \\
\text { (modality, } \\
\text { content) }\end{array}$ & $\begin{array}{l}\text { Offering a variety of options for formats of } \\
\text { student reflections as well as the content of } \\
\text { those reflections }\end{array}$ \\
\hline Familiar Contexts & $\begin{array}{l}\text { Contexts the student may have already } \\
\text { encountered reflection (e.g. journaling) }\end{array}$ \\
\hline Expectations & $\begin{array}{l}\text { The expectations for student reflections } \\
\text { (e.g. length of reflection, content) }\end{array}$ \\
\hline $\begin{array}{l}\text { Group Reflections } \\
\text { (building trust) }\end{array}$ & $\begin{array}{l}\text { Having students reflect in groups, taking } \\
\text { into consideration the need for trust within } \\
\text { a group for authentic reflection }\end{array}$ \\
\hline Transparency & $\begin{array}{l}\text { Disclosing the motivation behind process } \\
\text { surrounding coursework reflection (e.g. } \\
\text { intended skill development) }\end{array}$ \\
\hline Barriers & $\begin{array}{l}\text { Barriers to reflection (e.g. logistics, } \\
\text { discomfort, pre-existing bias) }\end{array}$ \\
\hline $\begin{array}{l}\text { Systems } \\
\text { Modelling + } \\
\text { Framework } \\
\end{array}$ & $\begin{array}{l}\text { How reflection is presented and framed to } \\
\text { students, and what influences how students } \\
\text { view reflection }\end{array}$ \\
\hline Student Strategy & $\begin{array}{l}\text { Strategies that students may use to avoid } \\
\text { reflecting with legitimate effort }\end{array}$ \\
\hline Grades/Feedback & $\begin{array}{l}\text { How students will be graded and/or how } \\
\text { feedback will be given on reflections }\end{array}$ \\
\hline Peer Evaluation & $\begin{array}{l}\text { Having peers grade or provide feedback to } \\
\text { other peers on their reflections }\end{array}$ \\
\hline $\begin{array}{l}\text { Behavioural } \\
\text { Modelling + } \\
\text { Exemplars }\end{array}$ & $\begin{array}{l}\text { Examples of reflection demonstrating value } \\
\text { in real scenarios (e.g. alumni presenting on } \\
\text { how they use reflection in their careers) }\end{array}$ \\
\hline $\begin{array}{l}\text { Specific } \\
\text { Examples }\end{array}$ & $\begin{array}{l}\text { Specific resources on the usage of } \\
\text { reflection (e.g. example reflections, videos) }\end{array}$ \\
\hline Scaffolding & $\begin{array}{l}\text { Frameworks, descriptions, and evaluation } \\
\text { tools to support the development of } \\
\text { reflection skills }\end{array}$ \\
\hline Well-Being & The mental wellness and health of students \\
\hline $\begin{array}{l}\text { Development } \\
\text { Pathway }\end{array}$ & $\begin{array}{l}\text { How reflective skills may progress as } \\
\text { students become more experienced }\end{array}$ \\
\hline Toolkit + Value & $\begin{array}{l}\text { Reflective skills framed as a toolkit of } \\
\text { skills and the associated value for the } \\
\text { purpose of professional development, } \\
\text { personal growth, life-long learning, etc. }\end{array}$ \\
\hline $\begin{array}{l}\text { Specific to } \\
\text { Engineering }\end{array}$ & $\begin{array}{l}\text { Considerations specifically for introducing } \\
\text { reflection to engineers }\end{array}$ \\
\hline
\end{tabular}

One concern when teaching reflection lies in students' pre-existing bias. Some students may believe reflection and writing assignments are boring, a chore, a waste of time, etc. This was stated by students in the focus groups even some experienced reflectors, who had been educated 
on reflection previously, did not think the process was worth the time investment. It is important to highlight the value students stand to benefit from reflection (e.g. employability, career advancement) so that they take it seriously. However, it is also important to be aware that not all students will care about reflection and see its value. Regardless of implementation technique, and given limited time in the curriculum, there will be a trade-off between convincing students of its value and working to help students develop their skills.

There were a variety of ways students in the focus groups had seen reflection implemented in classrooms: written prompts in lectures, journaling formats, essaylength written reflections, interviews, and group discussions were some examples. Students disagreed on which format(s) they learned from best. As such, a degree of flexibility may be necessary to allow students to $\mathrm{c}$ the format of reflection they feel they derive the most value from - especially when reflecting formally for the first time.

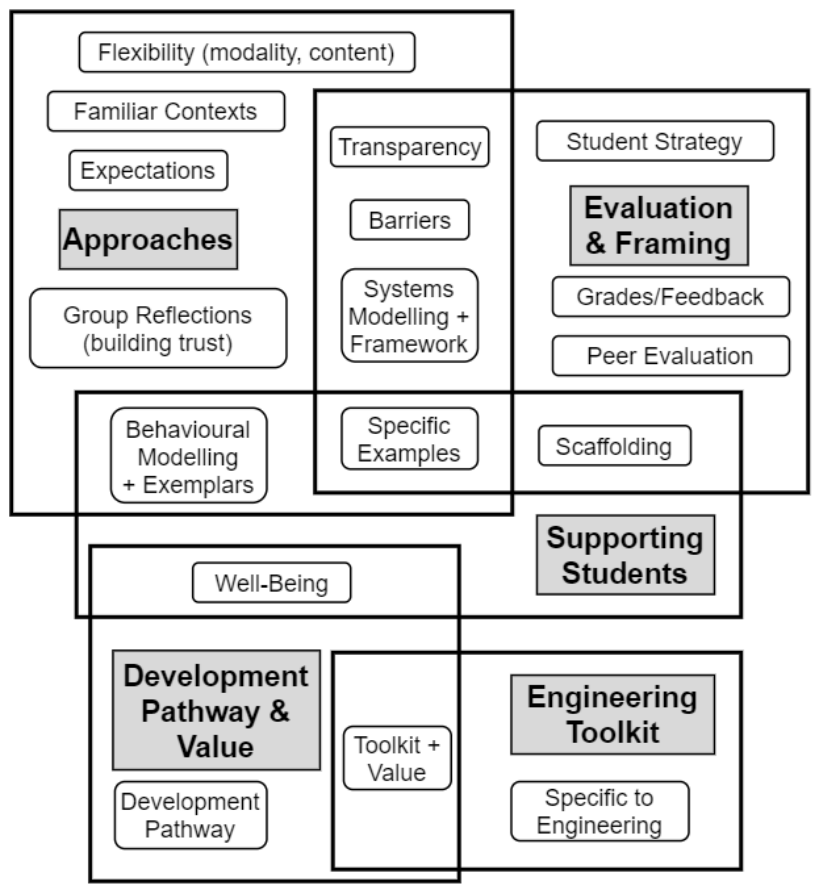

Fig. 1. Final themes (bold, shaded grey) for analysis with accompanying codes (white boxes with filleted edges).

Similarly, there is no clear best practice between asking students to reflect on academic (e.g. group projects, exams) or personal (e.g. personal goals, social contexts) topics. Personal topics can offer students more opportunity to cater their reflections to personal development or intrinsic motivations but may be perceived as irrelevant. Academic topics may be seen as more 'valuable' or relevant to some students while also being less interesting or thought-provoking to other students. The key consideration is to provide opportunities for students to learn reflection as a skill in a context that is most comfortable, and then to apply the skills to a different context as they become more developed. Additionally, it is important for the instructor to be transparent about expectations and evaluation structure for students to reflect honestly and thoughtfully, and not try to 'game the system'. For example, if there are no restrictions on word count, this should be communicated to students with an emphasis that the quality of the reflection is most important.

\subsection{Evaluation and Framing}

The evaluation structure of the reflections will play a key role in how reflection is framed in students' minds. Adding a formal grading structure may make reflections less genuine; with a grading scheme, students may feel that they need to hit checkboxes, and may not complete an authentic reflection focused on their learning. It may also frame reflection to students as having 'right' and 'wrong' answers. Alternatively, making reflections optional may also work to devalue reflections in students' eyes. Therefore tensions exist between associating grades to ensure students take reflection seriously, and avoiding making the reflection a high-stakes written assignment which causes undue stress for students.

Focus group participants were aware of the logistical challenges of evaluation, as evaluating hundreds of student reflections is challenging and resource intensive. However, formative feedback is key to helping students develop reflective skills, so assessment options which include feedback are encouraged. Potential solutions lie in marking schemes that incorporate random evaluation of a subset of submitted reflections to reduce the amount of evaluation needed while still encouraging the practice of reflection. The concept of in-person reflection also arose in several focus groups, with formats ranging from oneon-one reflective discussions with teaching assistants to large group discussions. The issue of privacy arises in these scenarios, for which there is no clear solution. Additionally, some students may not be comfortable with this format, presenting a barrier. This may be an additional opportunity for flexibility in approach, as students could engage in different formats they feel most comfortable with.

Peer evaluation is a plausible solution for evaluation; however, there was an overwhelming opinion amongst participants that having peers mark reflections for a numeric grade was a bad idea. Students new to reflection may be too overwhelmed or inexperienced to effectively grade their peers, or the evaluation may be unfair as some students may not care enough and will arbitrarily give peers excessively high or low grades. However, the idea of peers providing feedback was received positively. Anonymously providing feedback for peers provides a learning opportunity for students to further refine their 
own reflection skills. Completion marks were proposed wherein students receive marks for both completing their own reflections and their evaluations of others. Though any reflections shared between students would be anonymized, students still mentioned important privacy concerns regarding disclosure of identifiable personal information and online sharing. These concerns would need to be addressed in any peer evaluation structure.

Logistical barriers to evaluation are one of the most critical issues present in implementing reflection. Evaluation should be carefully considered by instructors based on course context, available resources, and desired learning outcomes, especially considering the influence of evaluation on student effort and value placed on developing reflection skills.

\subsection{Supporting Students}

When developing any new skill, learners often benefit from various forms of support. One form of support for students is that of the 'scaffolding' (structure/outline) provided with reflective assignments. This can include but is not limited to prompts, reflection frameworks, and evaluation rubrics. In the focus groups, students said that too much scaffolding (e.g. highly detailed rubrics) can make them feel restricted and mask the value of reflection. Conversely, too little scaffolding (e.g. vague prompts, no evaluation guidelines) can be scary and inhibit some students who may not know where to start. Scaffolding that is flexible (i.e. providing optional prompts) could provide structure for some, while also not restricting students who prefer open-ended reflections. Focus group participants overall indicated that the quality of reflections and the level of introspection in a reflection can be tied to the quality of the prompt and scaffolding that is provided to students, making it an important consideration for implementing reflection.

Supporting students in their pursuit of developing reflective skills can also be provided through specific examples and behavioural exemplars. Multiple students across the focus groups indicated that specific, concrete examples of reflection may help to make the concept less abstract and help students struggling to grasp the concept of reflection. However, there is a risk with providing detailed examples to students, namely that some students may try to copy the examples. Regardless, resources (e.g. examples, videos, additional prompts) should be easily accessible to help facilitate the development of their reflective skills. In addition to examples, behavioural exemplars (e.g. instructor talking about using reflection in their life, alumni presenting on their use of reflection in their careers) can be used to showcase to students how reflection is valuable beyond assignments.

Another aspect of supporting students is considering the negative impacts reflection can have. Reflection typically encourages students to analyze the negatives of an experience and consider how they may have improved their learnings or outcomes. While this can lead to selfgrowth and increased self-awareness, it can also cause students to fixate on negative outcomes. Additionally, if a student wrote a reflection on a sensitive topic, such as suicide or mental health struggles, it could have a adverse effects on someone reading the reflection for evaluation purposes. The act of writing and evaluating reflections can be emotionally draining, so mental health and wellbeing supports should be available and advertised to students and evaluators to ensure everyone involved in the process has the support they may need as they reflect. For example, on-campus student wellness resources, such as counselling or peer support groups, could be advertised through course administration platforms. Implications related to well-being are beyond the scope of this paper; however, reflection might serve as an additional avenue to reduce the stigma around mental health in academia.

\subsection{Development Pathway and Value}

One of the most intriguing takeaways from the focus groups was the concept of a development pathway for reflection. Critical reflection, as with most skills, is not a binary, "you have it or you don't" skill. Opinions and thoughts from focus group participants tended to range along a spectrum, so the team derived a model depicting the progressive development of reflection skills (Fig. 2). This model proposes that one's reflection abilities can be viewed on a scale, with the introductory end of the scale being unaware of critical reflection as a skill, and the more advanced end where reflective thinking is integrated into all aspects of daily life as a component of lifelong learning.

The stages along the development pathway can be linked to Bloom's taxonomy of cognitive processes [17]; cognitive processes become higher order further along the pathway. For example, in the introductory phase, students can understand the value of reflection, while in more advanced phases, the student critiques reflection formats, progressing from understanding to evaluating.

The final two stages of the pathway are cyclical as students, and all reflective practitioners, go through phases of learning and development. These two phases, 'Mindset' and 'Continuous Growth \& Learning', are comparable to two sub-components of metacognition: metacognitive knowledge, the awareness and application of reflection 'tools', and metacognitive regulation, the planning, maintenance, and adaptation of these 'tools' [18]. The 'metacognitive awareness cycle' illustrates the duality of these stages, where a student can apply highly developed reflective tools while also being aware of the lifelong learning opportunity to further develop their skills. 


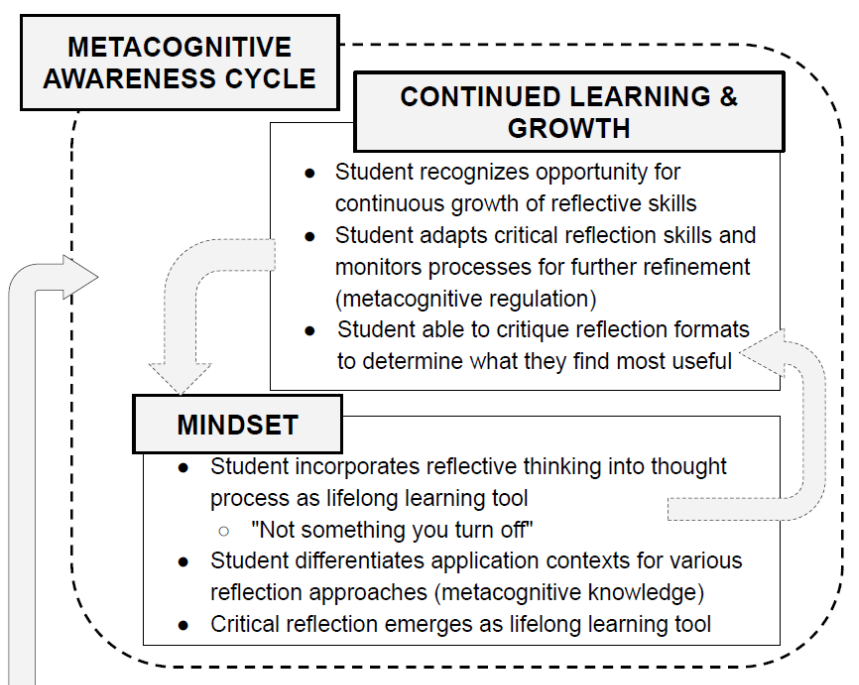

MATURATION

- Student relies less on rigid structures/scaffolding when reflecting

- Progression of reflective skills will take different forms for different students (e.g. more practice, using new formats)

- Student able to apply reflective skills to specific experiences to gain value

\section{INITIAL DEVELOPMENT}

- Student understanding is deepened through examples and other contexts

- Critical reflection skill development encouraged via practice and feedback

- Student understands the value of reflection on a superficial level

\section{INITIAL EXPOSURE}

Student introduced to reflection through supportive framework or prompts

- Critical reflection is seen as a skill (akin to other durable skills)

- Student exposed to value of reflection, but does not understand/appreciate the value

\section{BASELINE}

- Student may have critically reflected without realizing (e.g self-evaluations)

- Unaware of critical reflection as a concept

- Student is unaware of value associated with reflection

Fig. 2. Reflective skill development pathway stages, which include: student competency level, how students may progress at each stage, and how students can utilize

reflection and recognize its value. This pathway

progresses in a linear fashion, towards the final two stages

within a 'metacognitive awareness cycle', as reflection skills never truly stop developing.

It is beneficial to think about value derived from reflective skills in terms of the development pathway - the farther one is along the path, the more value they tend to derive from the reflective process. Reflection allows students to turn abstract thoughts into concrete learnings [19], extracting more value from individual experiences. Additionally, reflection can have positive impacts on students' well-being; students in the focus groups stated that reflection had helped them to identify areas of improvement, "break down unconscious cycles" of negative habits, and "get so much more out of failures" instead of being discouraged. While these benefits can come from even the most basic reflection when done correctly, the more skilled one becomes in reflection, the more one can learn from each experience they reflect on. Learnings from experienced reflectors revealed that repetition and feedback are two key elements in helping students to advance along this pathway.

The proposed development pathway is based on responses from focus group participants from a wide range of reflection competencies. However, this model verified and explicitly tested to identify threshold concepts which could serve as milestones, with associated learning interventions to help students develop their reflection skills. Although beyond the scope of this work, the model provides an initial starting point to better understand the potential development pathways students follow when learning how to critically reflect.

\subsection{Reflection for Engineers - The Engineering Toolkit}

The focus group participants pointed out that engineering students tend to be technically minded individuals who see written assignments as less important than technical assignments. First-year engineering students are learning to navigate busy schedules and new environments and have limited time to spend on assignments of little perceived value - they tend to focus on midterms and larger projects. Thus, a written reflection assignment only worth a few marks falls into the category of 'assignments to complete without much thought'. Specifically, for the purpose of first-year engineering students, reflection must be framed as valuable to them and implemented so that it fits in a busy schedule.

Reflection, and more broadly critical thinking and lifelong learning, can be seen as a toolkit of skills. Employers are increasingly looking for students who have not only a robust technical knowledge base, but also these important durable skills [4]. Thus, reflection and critical thinking can help students' employability, which can improve the benefits students perceive from developing reflective skills. In the focus groups, students emphatically responded that this should be highlighted when introducing reflection to students to increase interest and perceived value. By framing as a method of increasing employability, or being more successful in other courses, reflection could be better showcased as the tool that it is rather than a burden for engineers.

\section{CURRICULUM APPROACHES}

The results of the focus group were distilled into general considerations that would be beneficial for curriculum development. Implementation is highly 
specific to the constraints around course context (e.g. allocated class time, TA resources, etc.), so instructors should adapt these considerations accordingly.

\subsection{Intended Learning Outcomes}

With a limited amount of time to work with students, it is important to distill key learning outcomes students should meet by the end of the course. Examples of the progression of learning outcomes include:

Students should be able to...

- describe what critical reflection means to them,

- apply reflection techniques to produce a reflection based on a personal and/or academic experience,

- recount and critique different methods of reflection based on which they find most useful,

- articulate how reflection skills can be used as a tool for improving employability, and/or,

- create a plan to continue applying their reflection skills as tools for self-directed learning.

\subsection{Reflection Format and Development}

The focus groups revealed several possible activities that students could engage with to improve their reflective skills. These can be broadly split into two categories: written (i.e. reflection assignments), or verbal (i.e. group reflection discussions). Written reflections are the default mode for individual reflections; however, verbal reflections can offer the chance to evaluate many students at once and allows students to gain feedback and new perspectives from others in a rapid fashion. However, verbal reflections might not be suitable for students who do not feel comfortable reflecting in groups, especially on personal topics. To balance evaluation needs with the comfort of students, a hybrid of these two forms could be implemented. For example, students could be given the option to participate in a group reflective discussion but provided with the alternative of submitting a written reflection for evaluation.

The issue of content for the reflections is important and mentioned often by instructors. Having students reflect on course content may better relate the reflections to a specific course, but it can limit student interest and ability to customize reflections to personal development goals. One approach is to give students the opportunity to decide whether they reflect on academic or personal topics. For example, students may be introduced to reflection by completing reflection activities on personal topics to demonstrate the value of reflection, before transitioning to academic topics to tie reflection into the course. Since reflection is meant to be showcased as a tool applicable in any scenario, reflection could also be focused holistically on personal values.

Regardless of the activities that students complete on reflection, a strong support system should be in place to help their learning and development. This includes a strong and thoughtful introduction to the topic to properly convey what reflection is and its value when conducted in a critical manner, as well as flexible scaffolding to provide structure to those who need it. Specific examples and resources can be provided to allow students with interest in reflection to further develop their skills.

\subsection{Assessment}

It is important to reiterate that the method for evaluating the reflections can have a substantial influence on student perception of reflection. By assigning a significant portion of the course grades to reflection, one might risk making the reflection feel like a burden. If reflections are not assigned grades at all, it may work to devalue reflection and cause students to take the concept less seriously. The team recommends that evaluations of reflection are worth a small portion of the course grade, such as only for completion. This would be designed such that the grades are enough to be an encouraging factor, while still allowing for flexibility.

When reflections are conducted in a written format in a large course setting, there are logistical challenges to have teaching staff read each reflection, provide feedback, and evaluate. This difficulty increases if multiple written reflection assignments are conducted throughout the year, as is encouraged to promote the practice of reflective skills. Solutions could include implementing a random evaluation of reflections through the course, utilizing anonymous peer feedback, or having verbal reflection sessions for students who are comfortable. Additionally, feedback, independent of grading, is a critical component of encouraging development of students' reflective skills.

\section{CONCLUSIONS}

This study identified key considerations for the integration of critical reflection into first-year engineering curriculum in a manner that promotes the development of self-directed learning skills. Focus groups were run with relevant student populations to ensure the student perspective informed these considerations. Reflection involves strong student biases, so this perspective is essential to generate student buy-in.

The focus group data was qualitatively coded for analysis, with five distinct themes emerging. Approaches to reflection found that introducing it as a familiar concept and providing a variety of implementation methods (e.g. written assignments, in-class discussions) can help to facilitate student understanding. Supporting students in developing skills can be achieved using scaffolding, specific examples, and resources related to well-being. Key considerations around the evaluation structure, and its role in framing reflection, include anonymity requirements in peer evaluation, and how the evaluation scheme can influence a student's perceived value of reflection. Reflective skills were viewed to progress along a development pathway, which has ties to 
cognitive processes of Bloom's Taxonomy. Specific considerations for implementing reflection in engineering curriculum include being considerate of busy student schedules, as well as the importance of framing reflection as a toolkit of skills that have value in improving employability and future career success.

The key findings from the focus groups can be used to inform learning outcomes, student activities, including recommendations for both the format and content of reflections, and evaluation techniques. Synthesizing the focus group findings into key, implementable guidelines ensures that student perspectives are included when integrating critical reflection into the curriculum to develop student lifelong learning skills.

\section{Acknowledgements}

The authors wish to acknowledge the funding and support provided by the Paul R. MacPherson Institute and the affiliated Student Partners Program.

\section{References}

[1] "New courses redefine first-year engineering," The University of British Columbia, 2017. Available from https://flexible.learning.ubc.ca/case-studies/new-coursesredefine-first-year-engineering/

[2] Joel B. Frey, Sean Maw, Susan Bens, Jim Bugg, and Bruce Sparling, "Design of a Completely New First Year Engineering Program at the University of Saskatchewan Part II," in Proc. CEEA Canadian Engineering Education Conf., CEEC19 (Ottawa, ON ; 9-12 June 2019), 8 pp., 2019. https://doi.org/10.24908/pceea.vi0.13793

[3] "The Pivot: Transforming engineering education," McMaster University Faculty of Engineering, 2019. Available from https://www.eng.momaster.ca/news/pivottransforming-engineering-education

[4] Office of the CEO, Humans Wanted: How Canadian youth can thrive in the age of disruption. RBC, 2018, 44 pp. Available from https://www.rbc.com/dms/enterprise/ futurelaunch/_assets-custom/pdf/RBC-Future-SkillsReport-FINAL-Singles.pdf

[5] Hart Research Associates, It Takes More Than A Major: Employer Priorities for College Learning and Student Success. Washington, DC: Association of American Colleges and Universities and Hart Research Associates, 2013, 15 pp. Available from https://www.aacu.org/sites/ default/files/files/LEAP/2013_EmployerSurvey.pdf

[6] Catherine A. Cherrstrom, Cindy M. Raisor, and Debra Fowler, "Student Chemical Engineering Reflective ePortfolios: ChE Student Perceptions of Learning From Reflective ePortfolio Creation," Chemical Engineering Education, vol. 49, no. 3, pp. 157-166, 2015.

[7] David Boud, "Using journal writing to enhance reflective practice," New Directions for Adult and Continuing Education, pp. 9-18, 2001. Available from https://onlinelibrary.wiley.com/doi/pdf/10.1002/ace.16

[8] Lawrence R. Chen and Maria Orjuela-Laverde, "Implementing Reflective Writing in Large NonTechnical Engineering Courses," in Proc. CEEA
Canadian Engineering Education Conf., CEEC18, (Vancouver, BC; 3-6 June 2018), 4 pp., 2018.

[9] Kenneth P. Mineart and Matthew E. Cooper, "Evaluation of Student Reflection as a Route to Improve Oral Communication," Chemical Engineering Education, vol. 50, no. 3, pp. 176-192, 2016.

[10] Canadian Engineering Accreditation Board, 2019 Accreditation Criteria and Procedures. Engineers Canada, 2019, 122 pp. Available from https://engineerscanada.ca/sites/default/files/accreditation/ Accreditation-Criteria-Procedures-2019.pdf

[11] Kate Whalen and Antonio Paez, "Development of a new framework to guide, assess, and evaluate student reflections in a university sustainability course," Teaching \& Learning Inquiry, vol 7, no. 1, pp. 55-77, 2019. https://doi.org/10.20343/teachlearninqu.7.1.5

[12] Jacob Nielsen, Gunver Majgaard, and Erik Sørensen, "Self-Assessment and Reflection in a $1^{\text {st }}$ Semester Course for Software Engineering Students," in E-Learning Systems, Environments and Approaches: Theory and Implementation, Pedro Isaías et al. (eds.), pp. 263-275, 2015 \{ISBN 9783319058245$\}$

[13] Elizabeth Marquis, Varun Puri, Stephanie Wan, Arshad Ahmad, Lori Goff, Kris Knorr, Ianitza Vassileva, and Jason Woo E., "Navigating the threshold of student-staff partnerships: A case study from an Ontario teaching and learning institute," International Journal for Academic Development, vol. 21, no. 1, pp. 4-15, 2016. https://doi.org/10.1080/1360144X.2015.1113538

[14] Lucy Mercer-Mapstone, Sam L. Dvorakova, Kelly E. Matthews, Sophia Abbot, Breagh Cheng, Peter Felten, Kris Knorr, Elizabeth Marquis, Rafaella Shammas, and Kelly Swaim, "A Systematic Literature Review of Students as Partners in Higher Education," International Journal for Students as Partners, vol. 1, no. 1, 23 pp., 2017.

[15] Stephen Mattucci, Kate Whalen, Daniel Picone, Joshua Yachouh, Ahmed Fuad Ali, "Experiential Learning for Complimentary Credit: Course to Earn Credit for Extracurricular Involvement" in Proc. CEEA Canadian Engineering Education Conf., CEEC20, 7 pp., 2020.

[16] Danielle Pearlston, Elizabeth DaMaren, and Stephen Mattucci, "Reflections on Implementing a Students-asPartners Approach to Curriculum Development in Engineering," in Proc. CEEA Canadian Engineering Education Conf., CEEC20, 8 pp., 2020.

[17] Lorin W. Anderson, David R. Krathwohl, Peter W. Airasian, Kathleen A. Cruikshank, Richard E. Mayer, Paul R. Pintrich, James Raths, and Merlin C. Wittrock, $A$ Taxonomy for Learning Teaching and Assessing: A Revision of Bloom's Taxonomy of Educational Objectives (Abridged Edition ed.). New York: Addison, Wesley Longman, Inc., 2001, 336 pp. \{ISBN 0-8013-1903-X\}

[18] John H. Flavell, "Metacognition and cognitive monitoring: A new area of cognitive-developmental inquiry," American Psychologist, vol. 34, no. 10, pp.906911, 1979. https://doi.org/10.1037/0003-066X.34.10.906

[19] Alice Y. Kolb and David A. Kolb, "Learning Styles and Learning Spaces: Enhancing Experiential Learning in Higher Education," Academy of Management Learning \& Education, vol. 4, no. 2, pp. 193-212, 2005. 